\title{
Interpreting the Cultural and Academic Experiences of PhD Students from the Indian Sub-Continent and the Chinese Regions in Australian Universities
}

\author{
https://doi.org/10.3991/ijet.v15i19.15799 \\ Yasir Latif ${ }^{(\varpi)}$, Neil Harrison, Hye-Eun Chu \\ Macquarie University, Sydney, Australia \\ yasir.latifehdr.mq.edu.au
}

\begin{abstract}
This study aims to identify factors that can improve the cultural and academic experiences of East Asian PhD students attending Australian universities. We focus on two key aspects of students' academic performance in Australia: a sense of belonging and learning strategies applied by international students in Australian higher education. A systematic literature review is conducted to design a framework that can be applied to better understand the cultural and academic experiences of students from the two regions. The application of this framework highlights, how students from these regions are better equipped to succeed in research degrees in Australian universities when they know and understand the culturally appropriate learning strategies applied in the Australian higher education context and when they are supported to develop a new sense of belonging within the academic and wider culture. Paper concludes that a sense of belonging with Australian culture helps international to attain good cultural and academic experiences. In terms of learning strategies, a scientific learning strategy is more effective for East Asian $\mathrm{PhD}$ students from Chinese and the Indian sub-continent than participative learning strategies, adaptive learning strategies, and artistic learning strategies. This study suggests the Australian research supervisors must communicate East Asian $\mathrm{PhD}$ students to attain a sense of belonging with Australian academic culture and to follow the scientific learning strategy. Future East Asian $\mathrm{PhD}$ students should understand the Australian academic culture to avoid cultural shock during $\mathrm{PhD}$ candidature. Future researchers should verify the theoretically designed through qualitative, quantitative, or mixed-method research design.
\end{abstract}

Keywords- $\mathrm{PhD}$, culturally appropriate learning strategies; belonging; academic progress; academic culture.

\section{Introduction}

International students aim to attain the best educational experience, from worldrenowned universities. Of the top 300 universities in the world, 17 are Australian [1]. Consequently, Australia is a popular destination for university enrolment, with many international $\mathrm{PhD}$ students enrolling every year. The Australian education industry is 
worth AUD \$20.3 billion annually to the Australian economy [2]. The Department of Education and Training (DET) reports a substantial increase in the number of students from two Asian regions studying in Australian universities, first the Indian subcontinent, including Bangladesh, India and Pakistan and second, the students from China. These two regions constitute $43.74 \%$ of the world population [3]. In 2017, a total of 106983 students from the Indian Sub-continent and 231191 students from China were enrolled in Australian universities [4]. The growth of the Australian education industry correlates with positive student experiences [5]. Positive student experiences generally are linked with knowledge-building, skills-learning, and graduation whereas failure and academic dropout are associated with negative academic experience. There is a continuous increase in the international student dropout rate in Australian universities (from $14.86 \%$ in 2005 to $14.97 \%$ in 2015). This is a significant threat to the Australian economy in general and for the higher education (HE) industry in particular [6]. We argue that these dropout rates are associated with the cultural and academic challenges experienced by international students at their host universities which Department of education and training (DET) has identified as "situational experiences" [7]. This paper investigates the possible causes of the increase in dropout rates among $\mathrm{PhD}$ students from the Indian Subcontinent and China. This paper aims to articulate how students can be effective learners in Australian universities while also maintaining some sense of their home cultural identity. It explores through the literature how international students negotiate the difference between their homebased learning strategies and those strategies required for effective learning in Australian higher education. It thus focuses on how international students adapt to the Australian academic culture.

\subsection{Definitions}

Giraldo-García, et al. [8] have linked international student failure rates to the students' cultural and academic experiences. Manathunga [9] states that the most common cultural and academic challenges are dealing with cross-cultural emotions; understanding scenarios; miscommunications; differentiating rational and irrational things; understanding desires; ambiguities and pedagogical interactions. She relates these experiences to one's sense of belonging to the home or the host culture and the application of culturally appropriate learning strategies to attain better cultural and academic experiences. The sense of belonging indicates the personal bond of students with their home culture as compared with the new host culture. A learning strategy indicates a plan of action followed by students in their academic studies. For example, conceptual understanding is very important in the Australian academic system whereas knowledge-building is of key and comparatively greater importance in the Asian academic system [10]. This study understands student experiences based on four cultural theories related to the sense of belonging include: 
a) Cultural iceberg model [11]

b) Acculturation model [12]

c) Intercultural differences [13]

d) Cultural competence theory [14]

Learning theory includes (a) experiential learning theory which is also known as Kolb's learning styles [15]. These theories along with their relevant variables are given below in figure 1 .

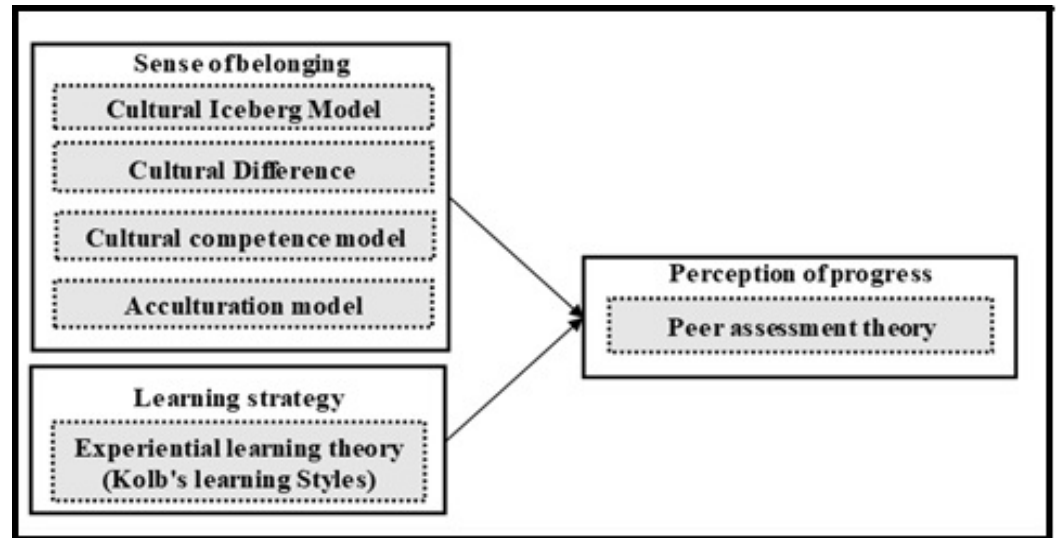

Fig. 1. Cultural and academic experiences: interplay of theories

The objective of this study is to provide students with a model that they can apply to become culturally and academically competent in the Australian academic culture. The paper draws on the research of Berry [12] acculturation theory and links it to the cultural competency theory developed by [14]. The paper also focuses on which culturally appropriate learning strategies required by $\mathrm{PhD}$ students to be successful in Australian universities and to this end we will explore the experiential learning theory. The paper now turns to investigate how international students experience the Australian academic culture.

\section{Cultural and Academic Experiences}

Each culture has its own prism through which it reflects the shared attributes of its members. Members of one culture fit well within their own culture irrespective of small individualistic differences. However, research students from the Chinese region and the Indian sub-continent in Australia universities can experience substantial problems due to cultural differences. Hofstede [13] has argued that cultures differ based on differences in cultural values. Different cultural values affect academic culture and can deprive international students of the needed opportunity to integrate with the host academic culture due to the difference in cultural values [16]. Cultural and academic integration of students helps them to reduce their dropout rates [17]. Tinto [18] has 
argued that building a community in host culture helps international students to succeed because it promotes their chances of interaction and integration to attain a sense of belonging with the new culture. Berry [12] has suggested that expatriates adopt certain adaptation strategies to integrate with the host culture. However, the ongoing question over recent years has centered on the personal costs of adapting to the host culture. Retaining one's cultural identity may lead to feelings of anonymity, isolation and cultural shock [9]. There is a need to increase the interaction of international students with their Australian colleagues. PhD students need to focus on linking themselves to Australian academic culture and relate their learning strategies to Australian academics through building a sense of belonging.

\subsection{Sense of belonging}

A sense of belonging is essential for community membership. It is "the experience of personal involvement in a system or environment so that persons feel themselves to be an integral part of that system or environment" [19]. It includes being valued, needed and accepted by various groups. Manathunga [9: 117] argues that a sense of belonging is a key issue for international students in Australia and other Western countries. Asian students at Australian universities have less familiarity with their socio-academic culture. Students feel themselves to be positioned in-between their home and the host culture and sense themselves as fragmented or incomplete [9]. The concept of "sense of belonging" to the home-host culture can be understood from four interlinked theoretical models: the cultural iceberg model [11]; the acculturation model [12]; intercultural differences [13]; and cultural competence theory [14].

Cultural iceberg model: Hall's cultural iceberg model posits that "understanding the reality of a covert culture and accepting it on a gut level comes neither quickly nor easily and it must be lived rather than read or reasoned" [11]. It indicates that international $\mathrm{PhD}$ students remain unable to understand the Australian academic culture unless they start interacting with this culture to reduce their perceived cultural differences to improve their sense of belonging, due to this reason cultural iceberg model comes under the sense of belonging in Figure1. It has been found that over time $\mathrm{PhD}$ students learn the hidden aspects of Australian academic culture through continuous intercultural comparisons, experiencing day-to-day habits, situational reactions, understanding laws, patterns and recurrence of specific attitudes and behaviors in particular scenarios. We refer to this understanding as "cultural awareness" as a systematic way to attain a sense of belonging. One attains cultural awareness after living and understanding the host culture over a longer period. Cultural awareness provides the logical connection between apparent practices and the hidden philosophies of society and accepting it after thorough understanding to improve the sense of belonging.

Cultural dimensions model: Cultural differences can be understood through three Hofstede dimensions, namely individualism/collectivism, uncertainty avoidance and power distance [20]. We shall explain it later. The difference between different countries or cultures depends upon cultural dimensions and can help us to understand the intercultural experiences of international research students. For example, if the dimensions of two cultures are closer to each other then it is more likely that $\mathrm{PhD}$ students 
may feel a stronger sense of belonging, while also experiencing fewer major cultural challenges in the new culture, this is why cultural differences come under the sense of belonging in figure1. Figure 2, based on three of Hofstede's dimensions, demonstrates how $\mathrm{PhD}$ students from various regions interact with feelings of power distance, individualism and uncertainty avoidance [20]. Power distance, the first dimension, indicates the extent to which a society accepts and tolerates an unequal distribution of power. A society with a higher value of power distance accepts more pressure, unjust behavior and irrational arguments because in high power distance society the concept of "might is right" prevails. A society lower value of power distance is more independent, reactive, law-abiding and more prepared to listen to experts or scholars because society only accepts those acts which are justifiable and logical. Australia, being a democratic and egalitarian country, does not allow centralization of power, preferring to promote independence, self-reliance and confidence in PhD students. Hofstede-Insight [20] suggests that power holders enjoy more prestige in high power distance countries such as Pakistan, India, Bangladesh and China. Power holders don't enjoy more prestige in low power distance societies such as Australia because authority and power isn't a determinant of prestige in Australia [20]. Low scores of power distance for Australia in Figure 2, indicate that Chinese PhD students in Australia may feel free, relaxed and less burdened while reporting to their academic supervisors, contrasting with the situation arising due to higher power distance scores encountered in the Chinese regions and the Indian sub-continent. Individualism/collectivism is Hofstede's second cultural dimension. It indicates the extent to which a member of a culture wants to be an individual or in a group. The collectivistic trait is associated with Asians whereas the individualistic trait is related to the Western students. Both the collectivistic and the individualistic traits program $\mathrm{PhD}$ students to behave in a fashion. The collectivistic drive of $\mathrm{PhD}$ students from the Chinese region and the Indian sub-continent associates them with problem-solving, following a reactive participation strategy to avoid shame, following trends for new developments, remaining in groups, striving for knowledge and valuing students on the basis of their performance [21, 22]. Ethical norms, supportive tendency and risk avoidance behavior in collectivistic cultures are the reasons for these behaviors. Therefore, $\mathrm{PhD}$ students from collectivistic cultures hardly argue with their research supervisors because it is considered immoral. Western individualistic culture programs Western PhD students to innovate and actively participate in self-development, building new ideas and understanding all the ways of learning. There is more personal development and self-improvement in Western countries. Self-improvement is sometimes seen in Asian societies as selfishness. Students from those Asian countries which enjoy greater proximity on the Geert Hofstede cultural calculator between their home country and Australia experience fewer cultural differences and adapt more to Australian academic culture [20]. For example, Indian PhD students are more able to adapt to Australian culture than Pakistani PhD students because their individualism score is 48 (see Figure 2), which is closer to the Australian individualism score of 90, whereas Pakistan has an individualism score of 14 which indicates that Pakistan is a collectivistic society. A low individualism score (Figure 2) indicates that PhD students will feel loneliness and a sense of being away from their own family as such a 
low score is also connected with less social interaction in the host culture [23]. The third Hofstede dimension indicates the extent to which the members of culture want reliability, certainty and consistency in a culture, for example, a higher value of uncertainty avoidance brings anxiety because uncertainty is there and people are using different methods to avoid it. A lower value of uncertainty avoidance brings predictability because there are less uncertainty and people do not feel the need to avoid uncertainty. Pakistan, Bangladesh, Taiwan, Japan and South Korea are less tolerant of uncertainty and want a more reliable, certain and consistent academic culture. $\mathrm{PhD}$ students from China and India manifest low levels of uncertainty avoidance as they have a higher ability to tolerate uncertain, unreliable and haphazard academic culture [20]. Students from Pakistan and Bangladesh don't like situations of flux, confusion, anxiety, ambiguity and suspicion, but are more likely to handle issues with ease in Australia due to a more reliable Australian academic culture, for example, Japanese students tolerate uncertainty more than Australian students [24]. Chinese and Indian $\mathrm{PhD}$ students may not care much if academic culture is uncertain. Put simply, if Australian academic culture becomes very uncertain, then students from Pakistan, Bangladesh, Taiwan, Japan and South Korea may panic, but Indian and Chinese students are more likely to remain stable.

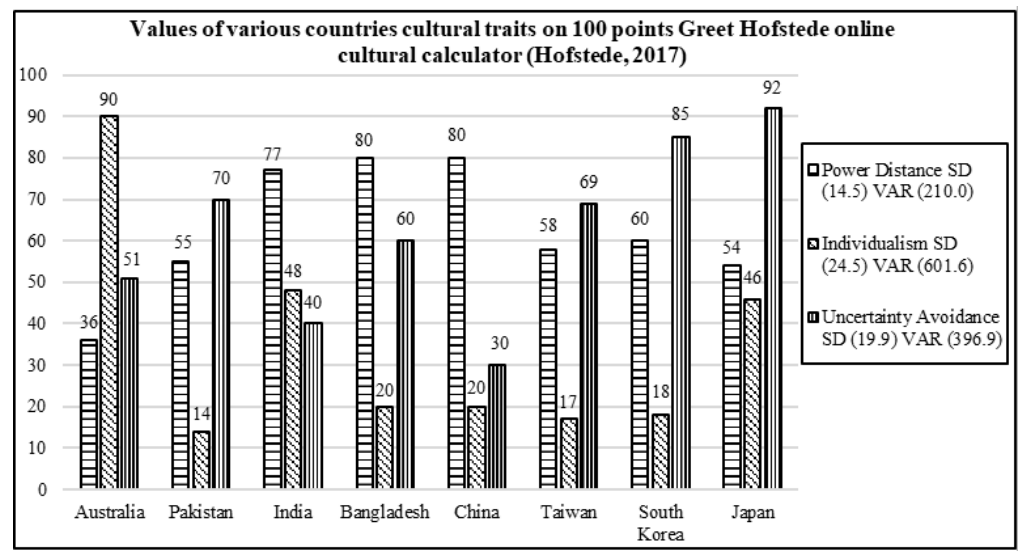

Fig. 2. Values of cultural traits

Berry's acculturation model: Berry's acculturation model can be defined as the cultural and psychological change arising in students in a host culture while also maintaining their own culture. He argues that participating in the host culture leads students to adopt four cultural strategies. The first strategy is integration, which states that students adopt the cultural traits of both the home and the host academic culture. The second strategy is assimilation, in which students adopt the traits of the host culture and leave the traits of their home academic culture behind [25]. Separation is a third strategy, which refers to opting for and adopting the home culture over the host academic culture. The last strategy is marginalization, in which students leave both academic cultures by adopting some other academic culture irrespective of any other factor. Berry [12] has suggested that assimilation and integration extend the bonds of 
international students with their host country which can help $\mathrm{PhD}$ students to attain a cultural sense of belonging so in figure 1 Berry's acculturation model is kept under the sense of belonging. Integration and assimilation strategies help $\mathrm{PhD}$ students from the Chinese region and Indian sub-continent to become members of the host academic culture and make progress, achieving success in their academic journeys. In contrast, separation and marginalization lead $\mathrm{PhD}$ students from the Chinese region and the Indian sub-continent to failure by keeping them away from the host academic culture. The reason is that academic suggestions, consultations and ideas exchange to increase the student's ability to perform better while solving the academic issues which separation and marginalization hinder.

Cultural competency model: Cultural competence is "the ability to communicate effectively and appropriately in intercultural situations based on one's intercultural knowledge, skills and attitudes" [14]. This communication is not limited to words but also to actions, non-verbal behavior, pronunciation, written and verbal content, trends, ways of thinking, feeling, modes of interaction and overall impression [26]. Academically this definition can be rephrased as an ability to study effectively and appropriately via intercultural academic exchanges within academic bodies, based on one's own academic knowledge, intercultural knowledge, academic skills and learning attitudes is known as academic cultural competency. Academic intercultural competence can help international research students to become members of the Australian research culture. For Berry [12] integration and assimilation lead to an integrative tendency and assimilative tendency respectively. The integrative tendency is the trait of high-performing students who are completely accustomed to and have adopted the shared and unshared salient features of both the home and host academic culture, guided by their personal preferences. As already discussed, integration reflects the adoption of the cultural and academic traits of both the home and host academic institutions. An integrative tendency indicates that $\mathrm{PhD}$ students can attain the good attributes of both the home and host academic culture, thus giving them competency in both. These tendencies promote the feelings of belongingness and acceptance due to which cultural competence comes under sense of belonging in figure 1 . The assimilative tendency is the trait of high-performing $\mathrm{PhD}$ students who make themselves culturally competent in the host academic culture $[12,14]$. These students compare their home and host countries and ultimately prefer the culture of their host country over that of their home country, due to personal preferences and levels of adaptability. The assimilative tendency indicates that $\mathrm{PhD}$ students feel more willing to leave the culture and academic traits of the universities of their home country and adopt the culture and academic traits of the universities of their host country. Following the above discussion, "academic intercultural incompetency" indicates the inability to study effectively and appropriately via intercultural academic exchanges within academic bodies, based on one's own academic knowledge, intercultural knowledge, academic skills and learning attitudes. $\mathrm{PhD}$ students then reflect a tendency to separate themselves from others. A separative tendency indicates the disposition of under-performing $\mathrm{PhD}$ students to opt for the home over the host culture. PhD students with an exclusive tendency marginalize themselves from both cultures and leave the home and the host academic cultures, due to a change in their preferences, affiliation and interest. Exclu- 
sive tendency comes with an interplay of cultural competency theory given by Deardorff [14] and marginalization strategy given by [12]. These PhD students may choose another interest or can adopt cultural traits of their own. In the light of the above discussion, $\mathrm{PhD}$ students can learn better by adopting integrative and assimilative tendencies because it can generate their interaction and exchange of learning strategies with Australian learners.

\subsection{Culturally appropriate learning strategies}

A learning strategy is "the way in which the learner selects, acquires, organizes, or integrates new knowledge"[27]. Learning strategies are situational and dependent on culture. Learning strategies differ according to different cultures because different cultures teach different methods to learn. Memorization, for example, is commonly referred to as a learning strategy among Asian students [28: 48-52]. Western academic culture focuses on independent learning and learner-centered approaches [28: 3] whereas Asian academic culture promotes a teacher-centered approach [28: ii]. The individualist characteristics of Western culture make scholars independent learners and the collectivistic features of Asian society encourage Asian scholars to be dependent learners due to their group orientation.

Four learning styles: Kolb [29] identifies four learning styles. The first style is based on feeling and watching. Kolb identifies this learning style as a diverging learning style. We define followers of the diverging learning style as artistic learners. Chinese, Japanese and Taiwanese students are generally more inspired by artistic methods to learn because they focus on imagination [30] and visualize concrete situations from many perspectives to generate ideas [31-33]. The second learning style involves thinking and doing and it is followed in English-speaking countries (USA, Canada, UK, and Australia) for practicability of ideas and theories [31, 32]. Kolb [29] identifies this learning style as a "converging learning style". We define followers of converging learning style "scientific learners". Scientific learners are those students who prefer technical and problem-based tasks over social and interpersonal tasks to progress in technical careers by using experimentation, scientific inquiry, technological and laboratory work. They focus on practical applications and the problem-oriented approach and follow single solutions using hypothetical deductive reasoning [30]; they prefer small group discussions, research group participation and computer-based learning aided by reliable data sources, to avoid risks [34]. The third learning style involves thinking and watching. Kolb identifies this learning style as the "assimilating learning style". We define followers of the assimilating learning style as "adaptive learners". The concept of adaptive learning was put forward by Bloom [35], who identified that individual guidance and supervising yields the best academic performance. However, individual guidance and supervision is available in the Australian universities but limited to particular time slots per week. In addition to the supervision of the research students, research supervisors also have their own projects so they can guide as an academic supervisor but cannot lead their students in their every issue. The Australian universities provide one to one supervisory support but also expect $\mathrm{PhD}$ students to work independently. Yuen and Lee [30] have suggested that PhD 
students who follow adaptive learning styles focus more on abstract concepts, concise information gathering and logical dimensions of theory for their scholarly interest rather for practical purposes. The fourth learning style involves feeling and doing. Kolb [29] identifies it as an "accommodating learning style". We define followers of the accommodating learning style as participatory learners. These learners are selfstarters and resolve a problem according to their gut feelings rather than using logical and analytical reasoning. They rely on experts to achieve tangible results rather than conducting their own analysis. Participative learners work well in action-oriented works, team projects and research fieldwork using the hit and trial method, due to their doer and feeler instincts [30]. These learners prefer computer-based simulation games and online group tasks using online resources. Western students become participative learners in a host academic culture [32]. Proper learning strategy can help $\mathrm{PhD}$ students to successfully graduate and this is possible if they can perceive their progress because it helps them to navigate and multiply their academic progress. Paper argues that scientific learning is the most favorable learning strategy for international research students followed by participative learning strategy, adaptive learning strategy and separative learning strategy. These results have been verified by [25].

\subsection{Perception of progress}

The literature on academic success talks about peer assessment rather than selfassessment on the path towards success. Keith Topping's peer-assessment definition is suitable for us to define "perception of progress". Perception of progress is a perceptual arrangement in which a learner considers the amount, level, value, worth, quality, or success or outcomes of their self-learning with reference to their past level of achievement, within a suitable system and framework of comparison, or based on a suitable relevant standard [37]. Perception of progress can be understood as perceived improvement in methods of learning through identifying, selecting, understanding, correcting, applying and remembering the solutions to the problems using new skills. Lim, et al. [38] have linked the peer learning for academic achievement. It is also a continuous effort of the $\mathrm{PhD}$ student to graduate under university standards and the supervisor's guidance. Research students estimate their academic contributions by aligning the academic outcomes of their efforts with given expectations [39].

\section{$3 \quad$ Methodology}

Literature review from 1980s-2019 has been comprehensively studied related to higher degree research students. Most of the studies were explicitly on PhD students studying in Western Universities and preferably in Australian universities. Several books and more than one hundred peer-reviewed articles are thoroughly studied. In addition, complete article readings, hundreds of peer-reviewed articles were also scanned by limiting the reading to their abstracts, methodologies and conclusions. A systematic literature review has been conducted by following the Kitchenham [42] guidelines of systematic literature review. The most important guideline is to conduct 
literature review according to predefined strategy instead of following preferred research hypothesis to ensure the completeness of the literature review. Bearman, et al. [43] guidelines are also similar to Kitchenham [42]. They have suggested that the literature review must be conducted in a comprehensive, structured and transparent method of searching and reviewing literature was adopted to identify the important elements of the model. The systematic literature review has helped to identify, evaluate and interpret all the relevant research available on the cultural and academic experiences of East Asian $\mathrm{PhD}$ students. The systematic literature review of cultural and academic experience literature has helped to identify the key elements of the model which contribute towards perception of the progress of $\mathrm{PhD}$ students in western host universities. The systematic literature review was conducted based on Google scholar search engine, ERIC, EBSCOhost, Scopus, Taylor and Francis, Emerald Insight, JStor, Science Direct, Wiley Online library and World Cat etc. Moreover, the academic news from Australian news channels, Australian Government bodies reports such as Department of Education reports related to student's completion and satisfaction rates, Department of Education and Training reports related to international student number, Australian Bureau of Statistics reports and interviews of Ministry of Education officials etc. University library support were also requested and used to retrieve the relevant information sources. Moreover, author has followed a unique approach to use one slide for one research paper to see the research trend. Additionally, researcher has also used the "text search query" in NVivo11 software to see the key variables which affect the student's success rate, perceived progress, graduation and degree completion.

\section{$4 \quad$ Findings}

Based on extensive literature review a model was built surrounding a list of five theories. The variables in these theories were majorly related with the perception of the progress. The developed model was based on an interplay of theories given below:

\subsection{The interplay of theories and their operation}

The interplay of theories given in the model shown in Figure 3 establishes the graduation process for $\mathrm{PhD}$ students in Australian academic culture by weaving the connective thread between learning, experiences, and culture. Nuankaew and Nuankaew [44] have suggested that to develop a model according to the context of the learner. The literature suggests that learning experiences and culture influence the progress of PhD students from the Chinese region and the Indian sub-continent. Cultural iceberg suggests a deep understanding of culture. Hofstede's intercultural differences help to differentiate cultures. Deardorff's cultural competence model helps to become a better and competent member of a culture. Berry's acculturation model helps to adopt a suitable cultural strategy for adapting host culture. The interplay of the models argues that Hall's cultural iceberg model, Hofstede's intercultural differences/dimensions model, Deardorff's cultural competency theory and Berry's accul- 
turation model are mutually inclusive, highly correlated and mutually supportive. They align with Kolb's theory of learning styles. The model yields a very helpful experiential process enabling PhD students from the Chinese and Indian sub-continent to graduate in Australia. The perception of progress helps these PhD students to predict their progress themselves towards graduation. The model in Figure 3 suggests that $\mathrm{PhD}$ students from the Chinese region and the Indian sub-continent have a greater tendency to fail if they focus on the surface or superficial attributes of Australian academic culture, maintain less interaction with host academic culture and have low intercultural awareness. This model shows that $\mathrm{PhD}$ students from the Chinese region and the Indian sub-continent have more potential to graduate if they focus on the deep attributes of that academic culture, maintaining more interaction with their host academic culture and fostering high intercultural awareness. Such an approach may assist them to adopt positive integration with Australian academic culture. This model connects several relevant theories to resolve the issues of sense of belonging and culturally appropriate learning strategies.

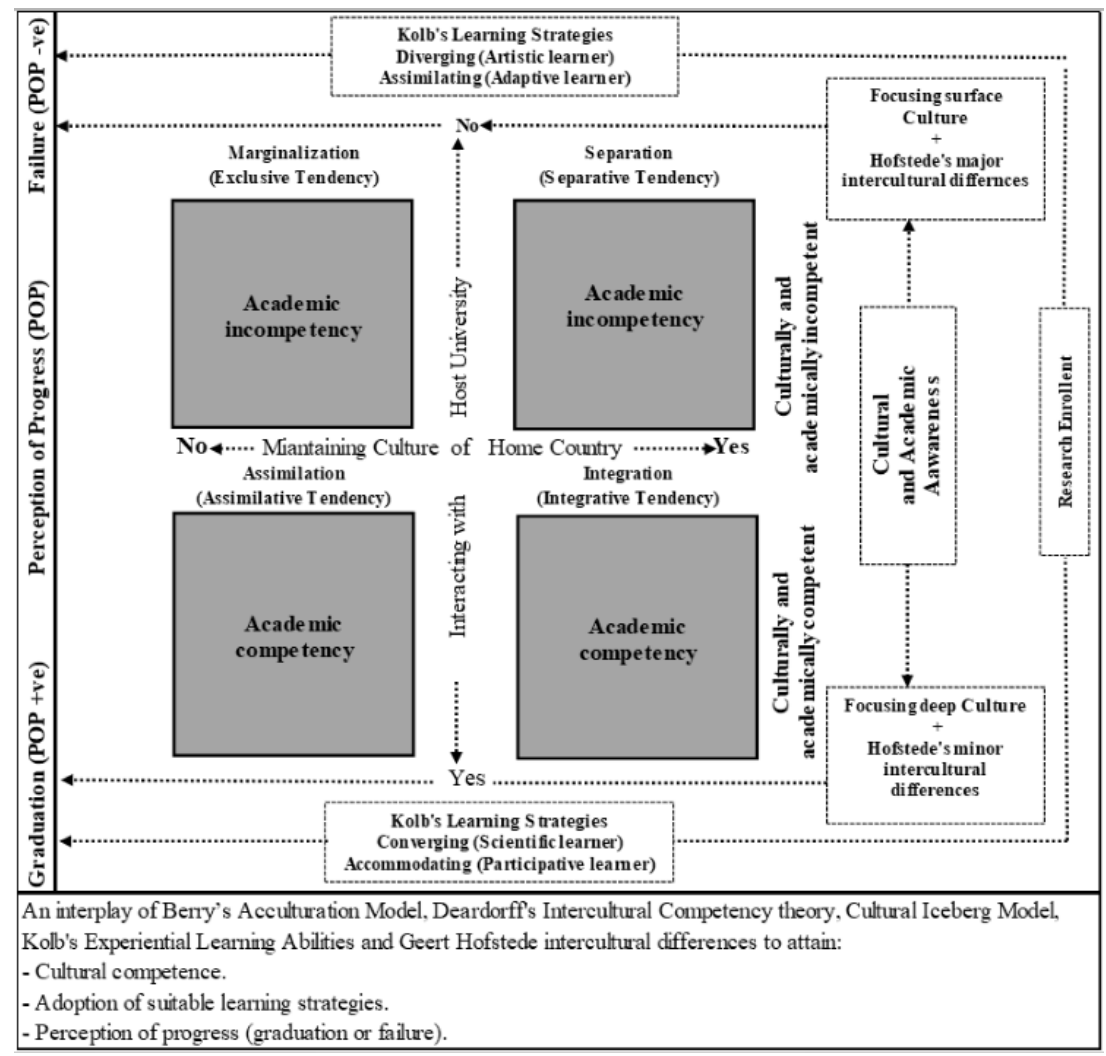

Fig. 3. An interplay of theories

Figure 3 highlights criteria that can assist $\mathrm{PhD}$ students from the Chinese region and the Indian sub-continent to interact more competently with the Australian aca- 
demic and research culture. Greater attention to deep cultural values can assist $\mathrm{PhD}$ students from the Chinese region and the Indian sub-continent to become culturally competent and increase their sense of belonging within the Australian academic sphere. In terms of culturally appropriate learning strategies, $\mathrm{PhD}$ students from the Chinese region and the Indian sub-continent need to adopt a converging learning style to become scientific learners and an accommodating learning style to become participative learners if they are to succeed in Australia. PhD students from the Chinese region and the Indian sub-continent need to be careful when focusing on the surface culture because separative and exclusive tendencies merely alienate the students.

\section{Conclusion and Recommendations}

It is difficult for a single theory to predict the impact of cultural and academic experiences of $\mathrm{PhD}$ students from Chinese region and Indian sub-continent in a host culture because cultural and academic experiences are too diverse for a single theory to cover, the application of several integrated theories together provides the theoretical power to enable in-depth understanding of the experience of $\mathrm{PhD}$ students from Chinese region and Indian sub-continent. We have suggested that students from these regions have more chances of success in Australian universities when they know and understand the culturally appropriate learning strategies applied in this context and have had the opportunity to develop a sense of belonging in the academic and wider culture. We suggest that Hall's cultural iceberg model (1989), Hofstede's intercultural differences model (1984), Deardorff's cultural competency model (2006) and Berry's acculturation model (1997) are mutually inclusive and supportive models that enable us to understand the sense of belonging required of students from the Chinese region and Indian sub-continent to succeed in Australian universities.

Kolb's experiential theory of learning styles (1984) help to understand the learning strategies of Asian students. Kolb's learning styles and Berry's acculturation models have some sort of correlation, but this still needs further investigation. This paper puts forward the new idea that $\mathrm{PhD}$ students from the Chinese region and the Indian subcontinent have more chances of success if they accommodate the learning strategies employed in Australian universities. However, $\mathrm{PhD}$ students from the Chinese region and the Indian sub-continent often feel a greater sense of belonging towards their home academic culture when they keep on following the learning strategies of their home academic culture. Western $\mathrm{PhD}$ students prefer to employ accommodating learning strategies over diverging and assimilating learning strategies. In brief, $\mathrm{PhD}$ students from the Chinese region and the Indian sub-continent are more likely to adopt a separative tendency by distancing them from Western academic culture. This paper proposes that $\mathrm{PhD}$ students Chinese and the Indian sub-continent can achieve intercultural competence in a host academic culture by applying the principles of Berry's integration-assimilation strategies. Similarly, PhD students from the Chinese and the Indian sub-continent learn better by employing a scientific learning strategy over adaptive and artistic learning strategies. Yasir, et al. [25] have suggested that the application of a scientific learning strategy is more effective for $\mathrm{PhD}$ students from Chinese and the Indian sub-continent than participative learning strategies, adaptive 
learning strategies and artistic learning strategies. These suggestive recommendations and conclusions may also apply to other international students, but this paper only limits the discussion to international research students in Australian universities. It is recommended to future researchers to study the model using qualitative and quantitative research. East Asian PhD students should understand the cultural differences. These students should build a sense of belonging with Australian culture through interaction with their Australian peers, university support services and wider Australian community beyond the university campus. Universities must make such arrangements in which it is make essential for East Asian students to interact with their Western peers. Moreover, universities must match the profiles and experiences of the supervisors with the cultural background of $\mathrm{PhD}$ students so the research supervisors can understand the strengths and weaknesses of the $\mathrm{PhD}$ students from East Asian region in Australian universities.

\section{References}

[1] QS. (2018, 26 February 2018.). QS World University Ranking. Available: https:// www.topuniversities.com/university-rankings/world-university-rankings/2018. https://doi. org/10.1201/9781315155890-7

[2] M. Schubert. (2016, 3 March 2018.). International education generates a record \$20.3 billion for Australia. Available: https:/www.universitiesaustralia.edu.au/Media-andEvents/media-releases/International-education-generates-a-record--20-3-billion-forAustralia\#.Wpjy4ehuaUl

[3] Worldometer. (2018, April 8, 2018). Countries in the world by population. Available: http://www.worldometers.info.

[4] DET. (2017, 2 February, 2018). International Student Data. Available: https://internationaleducation.gov.au/research/International-Student-Data/Documents/MO NTHLY\%20SUMMARIES/2017/International\%20student\%20data\%20December\%20201 7\%20detailed\%20summary.pdf

[5] C. Nyland, H. Forbes-Mewett, and C. E. Härtel, "Governing the international student experience: Lessons from the Australian international education model," Academy of Management Learning \& Education, vol. 12, no. 4, pp. 656-673, 2013. https://doi.org/10.5465/ amle.2012.0088

[6] B. Robert. (2015, 2 May 2017.). Universities fail to reduce dropout rates, Simon Birmingham blames uni performance. Available: http:/www.afr.com/news/policy/education/ universities-fail-to-reduce-drop-out-rates-simon-birmingham-blames-uni-performance-20 171114-gzl0b2\#ixzz56TtS6JlW

[7] DET. (2016, 20 March 2018). Student Experience Survey results released. Available: https://www.education.gov.au/news/2015-student-experience-survey-results-released

[8] R. J. Giraldo-García, A. Galletta, and J. G. Bagaka's, "The intersection of culture and institutional support for Latino students' academic success: Remediation or empowerment?" Journal of Latinos Education, vol. 18, no. 1, pp. 68-80, 2019. https://doi.org/10.1080/1534 $\underline{8431.2018 .1426464}$

[9] C. Manathunga, Intercultural postgraduate supervision: Reimagining time, place and knowledge. Routledge, London and New York: Florence Production Ltd, Stoodleigh, Devon, UK, 2014, pp. 1-212. https://doi.org/10.4324/9780203111956 
[10] L. Yang, "Institutional Performance, Institutional Change, and Building a KnowledgeDriven Society," in Knowledge-Driven GovernanceBejing, China: Springer, 2019, pp. 113-134. https://doi.org/10.1007/978-981-13-2910-4 6

[11] E. T. Hall, Beyond culture. Anchor, 1989.

[12] J. W. Berry, "Immigration, acculturation, and adaptation," Applied Psychology, vol. 46, no. 1, pp. 5-34, 1997.

[13] G. Hofstede, Culture's consequences: International differences in work-related values. Sage Publications, Newbury Park, California., 1984.

[14] D. K. Deardorff, "Identification and assessment of intercultural competence as a student outcome of internationalization," Journal of studies in international education, vol. 10, no. 3, pp. 241-266, 2006. https://doi.org/10.1177/1028315306287002

[15] D. A. Kolb, R. E. Boyatzis, and C. Mainemelis, "Experiential learning theory: Previous research and new directions," Perspectives on thinking, learning, and cognitive styles, vol. 1, pp. 227-247, 2001. https://doi.org/10.4324/9781410605986-9

[16] H. K. Bhabha, "Diaspora and home: An interview with Homi K. Bhabha," in Language and culture, K. Stierstorfer, Ed., ed. Schloss Wilkinghege, Münster, Germany: De Gruyter, 2013. https://doi.org/10.1515/9783110408614-002

[17] L. Willcoxson, J. Cotter, and S. Joy, "Beyond the first-year experience: the impact on attrition of student experiences throughout undergraduate degree studies in six diverse universities," Studies in Higher Education, vol. 36, no. 3, pp. 331-352, 2011. https://doi.org/10.10 $\underline{80 / 03075070903581533}$

[18] V. Tinto, "Building community," Liberal Education, vol. 79, no. 4, pp. 16-21, 1993.

[19] B. M. Hagerty, J. Lynch-Sauer, K. L. Patusky, M. Bouwsema, and P. Collier, "Sense of belonging: A vital mental health concept," Archives of psychiatric nursing, vol. 6, no. 3, pp. 172-177, 1992. https://doi.org/10.1016/0883-9417(92)90028-h

[20] Hofstede-Insight. (2017, June 3, 2017). Compare countries. Available: https://www.hofstede-insights.com/country-comparison/bangladesh,pakistan,south-korea,t aiwan/

[21] J. Knausenberger and G. Echterhoff, "Recovering from social exclusion: The interplay of subtle Facebook reminders and collectivistic orientation," Computers in Human Behavior, vol. 78, pp. 298-305, 2018. https://doi.org/10.1016/j.chb.2017.10.012

[22] R. Ali, K. Khurshid, A. Shahzad, I. Hussain, Z. A. Bakar, and M. Valcke, "Nature of Conceptions of Learning in a Collectivistic Society: A Qualitative Case Study of Pakistan," Eurasia Journal of Mathematics, Science and Technology Education, vol. 14, no. 4, pp. 1175-1187, 2018. https://doi.org/10.29333/ejmste/81867

[23] Hagerty and A. Williams, "The effects of sense of belonging, social support, conflict, and loneliness on depression," Nursing research, vol. 48, no. 4, pp. 215-219, 1999. https://doi. org/10.1097/00006199-199907000-00004

[24] S. Sugahara and G. Boland, "The role of cultural factors in the learning style preferences of accounting students: A comparative study between Japan and Australia," Accounting Education: an international journal, vol. 19, no. 3, pp. 235-255, 2010. https://doi.org/10.1080/0 $\underline{9639280903208518}$

[25] L. Yasir, H. Neil, and C. Hye-Eun, "Impact of dimensions of learning strategies and sense of belonging on academic progress and research progress of international research students in Australian universities.," PhD Thesis, 2019.

[26] C. Elder, T. McNamara, H. Kim, J. Pill, and T. Sato, "Interrogating the construct of communicative competence in language assessment contexts: What the non-language specialist can tell us," Language \& Communication, vol. 57, pp. 14-21, 2017. https://doi.org/10.10 16/j.langcom.2016.12.005 
[27] C. Weinstein and R. Mayer, "The teaching of learning strategies.," Innovation Abstracts, vol. 5, no. 32, pp. 1-4, 1983.

[28] A. Bakar, "A Study of Asian Students' Perceptions of Learning Strategies and Related Issues in UK Based Higher Education Institutions," Ph.D. thesis, University of Worcester, University of Worcester, UK, 2013.

[29] D. Kolb, "Experiential learning as the science of learning and development," ed: Englewood Cliffs, NJ: Prentice Hall, 1984.

[30] C.-C. Yuen and S. N. Lee, "Applicability of the learning style inventory in an Asian context and its predictive value," Educational and Psychological Measurement, vol. 54, no. 2, pp. 541-549, 1994. https://doi.org/10.1177/0013164494054002029

[31] Y. Yamazaki and D. C. Kayes, "Expatriate learning: Exploring how Japanese managers adapt in the United States," in annual meeting of the Academy of Management, Honolulu, Hawaii, 2005. https://doi.org/10.1080/09585190701502521

[32] Y. Yamazaki and D. C. Kayes, "Expatriate learning: Exploring how Japanese managers adapt in the United States," The International Journal of Human Resource Management, vol. 18, no. 8, pp. 1373-1395, 2007. https://doi.org/10.1080/09585190701502521

[33] P. Auyeung and J. Sands, "A cross cultural study of the learning style of accounting students," Accounting \& Finance, vol. 36, no. 2, pp. 261-274, 1996. https://doi.org/10.1111/j. 1467-629x.1996.tb00310.x

[34] B. L. Delahaye, Human resource development adult learning and knowledge management. Brisbane, Australia.: John Wiley \& Sons, 2004, pp. 1-471.

[35] B. S. Bloom, "The 2-sigma problem: The search for methods of group instruction as effective as one-to-one tutoring," Educational researcher, vol. 13, no. 6, pp. 4-16, 1984. https:// doi.org/10.3102/0013189x013006004

[36] M. Motter-Hodgson, "Meeting the needs of diverse types of learners," CyberCorp Inc's newsletter, pp. 1-3, 1998.

[37] K. Topping, "Peer assessment between students in colleges and universities," Review of Educational Research, vol. 68, no. 3, pp. 249-276, 1998. https://doi.org/10.3102/00346543 $\underline{068003249}$

[38] C. L. Lim, H. Ab Jalil, A. M. Ma'rof, and W. Z. Saad, "Peer Learning, Self-Regulated Learning and Academic Achievement in Blended Learning Courses: A Structural Equation Modeling Approach," International Journal of Emerging Technologies in Learning, vol. 15, no. 03, pp. 110-125, 2020. https://doi.org/10.3991/ijet.v15i03.12031

[39] K. McKenzie and R. Schweitzer, "Who succeeds at university? Factors predicting academic performance in first year Australian university students," Higher education research \& development, vol. 20, no. 1, pp. 21-33, 2001. https://doi.org/10.1080/07924360120043621

[40] K. E. Matthews, J. M. Lodge, and A. Bosanquet, "Early career academic perceptions, attitudes and professional development activities: questioning the teaching and research gap to further academic development," International Journal for Academic Development, vol. 19, no. 2, pp. 112-124, 2014. https://doi.org/10.1080/1360144x.2012.724421

[41] S. Eng, K. Kanitkar, H. H. Cleveland, R. Herbert, J. Fischer, and J. D. Wiersma, "School achievement differences among Chinese and Filipino American students: Acculturation and the family," Educational Psychology, vol. 28, no. 5, pp. 535-550, 2008. https://doi.org/ $10.1080 / 01443410701861308$

[42] B. Kitchenham, "Procedures for performing systematic reviews," in "Keele, UK," Keele University2004, vol. 33.

[43] M. Bearman et al., "Systematic review methodology in higher education," Higher Education Research Development, vol. 31, no. 5, pp. 625-640, 2012. 
[44] W. Nuankaew and P. Nuankaew, "The Study of the Factors and Development of Educational Model: The Relationship between the Learner Context and the Curriculum Context in Higher Education," International Journal of Emerging Technologies in Learning, vol. 14, no. 21, pp. 205-226, 2019. https://doi.org/10.3991/ijet.v14i21.11034

\section{$7 \quad$ Authors}

Yasir Latif is doing $\mathrm{PhD}$ on doctoral students experience at Macquarie University.

Neil Harrison is an associate professor in Macquarie University. His interests include educational philosophy, ethics, psychoanalysis, and phenomenology.

Hye-Eun Chu is a senior lecturer in Department of Educational Studies, Macquarie University, Sydney. Her research has been focused in the STEM areas.

Article submitted 2020-05-27. Resubmitted 2020-06-27. Final acceptance 2020-06-29. Final version published as submitted by the authors. 